\title{
Melioidosis: Indian perspective
}

\author{
T Karuna ${ }^{1}$, Khadanga $S^{2}$, Dugar $D^{3}$.
}

${ }^{1}$ Dr T Karuna, Assistant Professor, Department of Microbiology, AIIMS, Bhopal, Madhya Pradesh, India. ${ }^{2}$ Dr Sagar Khadanga, Associate Professor, Department of Medicine, L N Medical College, Bhopal, Madhya Pradesh, India. ${ }^{3}$ Dr Dharmendra Dugar, Assistant Professor, Department of Surgery, Hi tech Medical College, Bhubaneswar, Odisha, India.

Address for correspondence: Dr T Karuna, Email: karunakhadanga@yahoo.co.in

\begin{abstract}
There has been an upsurge of melioidosis cases in India in recent past. Lack of awareness of this disease among the Indian clinicians and microbiologists is responsible for the wrong diagnosis as tuberculosis, scrub typhus, leptospirosis and brucellosis. Being one of the most potent emerging infections in India the clinicians and microbiologists should be suspicious of this organism in any suppurative lesions at multiple sites. Though B.pseudomallei has been most commonly reported in diabetic and immune compromised hosts, immunocompetency does not rule out its presence. All suspicious samples should be incubated for 5-7 days to isolate the organism. They should be treated for 10-14 days as Intensive therapy in the hospital with sensitive intravenous antibiotic followed by 3-6 months of oral therapy with Cotrimoxazole for complete eradication.
\end{abstract}

Keywords: Melioidosis, Burkholderia pseudomallei, Immunocompromised host

\section{Introduction}

In 1911 Indian bacteriologist C.S. Krishnaswami, under the able guidance of the pathologist Alfred Whitmore, described a "Glanders-like" disease among the morphin addicts in Rangoon, Burma [1, 2]. Melioidosis was coined from the Greek words "melis," which means "distemper of asses," and "eidoes," which means "resemblance," by Stanton and Fletcher in 1932[3]. Since then, thousands of cases have been reported all over the world, predominantly from Southeast Asian countries (Thailand, Malaysia, Indonesia) and Australia.

The causative agent has been named variously since its identification by Alfred Whitmore; Bacillus whitmori, Bacillus pseudomallei, Malleomyces pseudomallei, Pseudomonas pseudomallei and since 1992, it has been called Burkholderia pseudomallei [4]. The first report of melidosis from India was by Rghavan et al from Mumbai in 1991[5]. Awareness of this disease among the Indian clinicians and microbiologists is poor leading to the under or mis diagnosis of the cases. Most of the cases of melioidosis are wrongly diagnosed as tuberculosis, scrub typhus, leptospirosis and brucellosis.

\section{Epidemiology}

Manuscript received: $04^{\text {th }}$ April 2014

Reviewed: $13^{\text {th }}$ May 2014

Author Corrected: $20^{\text {th }}$ May 2014

Accepted for Publication: 24 $4^{\text {th }}$ May 2014
In the latter half of the $20^{\text {th }}$ century, melioidosis emerged as an infectious disease of major public health importance in South East Asian Region. Maximum cases of melioidosis have been reported from Thailand where it is widely distributed in soil and in pooled surface water such as in rice paddies. B. pseudomalleus is considered to have potential in biological warfare, and is regarded as a potential bioterrorist weapon. It appears on the category B list of the critical agents published by the US Centers for Disease Control and Prevention [6].

Melioidosis gained the lime light, when it was reported to be one of the most potent emerging infections in India in 1996[7]. Since the first case reported from Mumbai in 19991, about fifty cases of melioidosis have been reported predominantly from southern part of India.

Though most of the cases have been reported from south India, but actually they originated from the eastern and western coastal belts. Maximum cases have been related to West Bengal where it seems to be endemic. $B$. pseudomallei, like many other soil bacteria, is a difficult organism to kill.

It can survive in a variety of hostile conditions like nutritional deficiency, acid and alkaline $\mathrm{pH}$, disinfectants, antiseptic solutions, exposure to many antibiotics, and extremes of temperature [8]. There is a strong association 
between monsoon rain, occupational and recreational exposure to surface muddy water and melioidosis [8].

Other than rainfall, physical factors like humidity, UV radiation, and temperature and chemical factors like soil composition, other vegetation, and use of fertilizers may influence the distribution of $B$. pseudomallei in the soil.

The route of transmission is by inhalation of contaminated dust or droplets, direct contact with contaminated soil or water through penetrating wounds and existing skin abrasions, aspiration of contaminated water, or ingestion [8]. In a few cases, it is reported to be nosocomial, sexually transmitted, or laboratory acquired.

\section{Immunopathogenesis}

After internalization, it escapes from endocytic vacuoles and spreads from cell to cell for intracellular survival. It is resistant to complement, lysosomal defensins, and cationic peptides, and produces proteases, lipase, lecithinase, catalase, peroxidase, superoxide dismutase, hemolysins, a cytotoxic exolipid and at least one siderophore $[9,10,11,12]$. By virtue of all these above mentioned features $B$. pseudomallei survives inside several eukaryotic cell lines and is seen within phagocytic cells in pathological specimens $[12,13,14]$.

The cell wall lipopolysaccharide (LPS) and the highly hydrated glycocalyx polysaccharide capsule of are important determinants of virulence, which help to form slime, protect the organism from antibiotic penetration, and alter the phenotypic character of the organism, resulting in reduced susceptibility to antibiotics $[15,16,17,18]$. The high mortality of $B$. pseudomallei infections is related to an increased propensity to develop high bacteremias ( $>1 \mathrm{cfu} / \mathrm{ml})$ [19].

Septicemic melioidosis is associated with very high concentrations of both pro-inflammatory and antiinflammatory cytokines - tumor necrosis factor (TNF), interleukin-6, interleukin-10, interferon-gamma, and interleukin-18 [18,19,20,21].

The concentrations of interleukin- 6 and interleukin-10 are independent predictors of mortality [21]. Antibodies against LPS components have been demonstrated to be protective. Antibody level was the highest for IgG (IgG1 and $\operatorname{IgG}$ ) [22]. Antibodies can persist variably over 3 years.

\section{Clinical feature}

A number of risk factors for developing melioidosis have been described; diabetes mellitus, thalassemia, renal disease, chronic lung disease, chronic alcoholism, occupational exposure to soil and surface water, elderly ( $>45$ years) males, and immunosuppression due to any cause [8]. Incubation period is usually 1-21 days, but can be as long as months and even years [25].

A number of risk factors for developing melioidosis have been described in various articles. Patients with diabetes mellitus have been reported to have a causal association with melioidosis.

Other than that, risk factors like thalassemia, renal disease, chronic lung disease, chronic alcoholism, occupational exposure to soil and surface water, elderly ( $>45$ years) males, and immunosuppressed state due to any cause may make the population susceptible [8]. Incubation period is usually 1-21 days, but can be as long as months and even years [25].

Clinical presentation of melioidosis varies widely. Clinical presentation of melioidosis varies widely. It ranges from asymptomatic infection, acute fulminant sepsis, sub acute multifocal abscesses to a chronic mild infection [26]. Chronicity (symptoms persisting more than 2 months) has an incidence of about $11 \%$ [25].

Maximum cases of chronic cases have been reported in Vietnam War experience described as "Vietnam timebomb," which manifested later in life as tuberculosis like disease [6]. The most common presentation is community-acquired pneumonia. However, many patients presenting with prolonged fever, weight loss, and suggestive chest $\mathrm{X}$-ray findings are misdiagnosed as tuberculosis and may get antitubercular therapy.

Other than that, there are patients with septic arthritis, multiple abscesses in liver, spleen, prostatic abscess (more in Australia), suppurative parotitis (more in Thailand), osteomyelitis, pyomyositis, cellulitis, fasciitis, skin abscesses or ulcers, and bacteremia with or without focus. On radiograph, Swiss-cheese appearance of the deepseated abscess in liver, spleen, or in other organs is seen. Mortality rate in Indian setup varies from 7 to $20 \%$ [27, $28]$.

\section{Laboratory diagnosis}

The protean manifestations of melioidosis often lead to clinical under-diagnosis of this fatal disease. Confirmation of melioidosis relies heavily on clinical microbiology laboratories and specifically on bacterial isolation by culture methods.

Though Serological and molecular methods have been evaluated in clinical settings, culture is still considered the gold standard.

Available online at: $\underline{\text { www.ijmrr.in }} 243$ | P a g e 


\section{Culture of B. pseudomallei}

Common specimens that yield B. pseudomallei on culture are blood, bone marrow, pus, fluid aspirates, tissue, throat swab, sputum, broncho-alveolar lavage (BAL) fluid, urine and ascitic fluid. Standard specimen collection and transport principles are sufficient.

Moreover, overgrowth of commensals from non-sterile sites (sputum), suboptimal selection of culture media, not using selective enrichment broth or agar, dismissal of the growth as contaminating non-fermenters from non-sterile sites, and discarding the culture plates by 3 days when the growth of B. pseudomallei may take 5-7 days in many occasions makes the diagnosis difficult.

Blood and bone marrow cultures can be done using conventional or automated blood culture system. Growth occurs within 5 days in conventional cultures and in 2 days in automated cultures. Hence, extended incubation is not required [29]. All plates are incubated at $35^{\circ}-37^{\circ} \mathrm{C}$ for up to 5-7 days. Any culture suspected of $B$. pseudomallei should be handled in class 2 biological safety cabinets (BSC II).

Colonies are often small, smooth, and creamy in the first 1-2 days on sheep blood agar, which gradually change after a few days to dry and wrinkled colonies.

Distinctive musty or earthy odor is encountered while opening the Petri plates. Pink or colorless colonies are seen on MacConkey agar after 1-2 days with metallic sheen. After 3-4 days, the colonies may become dry and wrinkled.

Asdown's media and modified Asdown's media has been described as the selective media which contain tryptase soy agar with glycerol, crystal violet, neutral red, and Gentamicin (4 mg/l). Colonies of B. pseudomallei on Ashdown agar are pinpoint, clear, and pale pink at $24 \mathrm{~h}$, changing to pinkish purple, flat, and slightly dry with sheen in the next 2 days.

After 5-7 days, the colonies get characteristic wrinkled appearance (rugose, or cornflower head) and they take up crystal violet from the medium [30].

\section{Rapid detection methods}

Although a variety of rapid antigen detection methods have been studied, none are commercially available yet. Among these, latex agglutination is evaluated for identification of culture or blood culture supernatants in Thailand and demonstrated sensitivity $95.1-100 \%$ and a specificity of $99.7-100 \%$ [31].

International Journal of Medical Research and Review
Similar results are shown in a study from Vellore using in-house co-agglutination test and latex agglutination test

[32]. In Thailand, the results of rapid immunofluorescence (IF) test and those of an existing IF method were prospectively compared with the culture of various clinical specimens from patients with suspected melioidosis.

The sensitivities of both IF tests were $66 \%$ and the specificities were 99.5 and $99.4 \%$, respectively [33].

\section{Antibody detection}

Indirect hemagglutination assay (IHA) remains the most widely used test despite its poor sensitivity and specificity in acute cases due to background seropositivity as a result of environmental exposure in endemic areas.

These facts have limited the diagnostic utility of IHA in acute melioidosis. Immunochromatographic tests have also demonstrated similar results and presented an enhanced performance over IHA [34].

Enzyme-linked immunosorbent assays (ELISAs) used on affinity-purified antigen, crude antigen, LPS, and extracellular polysaccharide (EPS) have been validated in clinical context with varied ranges of sensitivity (63.9$82.4 \%$ ) and specificity (71.1-82.1\%) [35]. Overall, IgG detection and not IgM appears to be a more sensitive indicator of clinical disease [36].

\section{Molecular diagnosis}

Delay in obtaining the culture results and inability of the serological methods in achieving accurate diagnosis have led to the search for accurate and rapid tools such as polymerase chain reaction (PCR).

Primers targeting 23S rRNA, 16S rRNA, and 16S and 23S RNA junction and TTS1 gene have been evaluated both on bacterial cultures and clinical specimen.

All PCR protocols showed accurate results in confirming the bacterial isolate after culture, while their sensitivity and specificities varied on testing the clinical specimen directly.

Low number of bacteria in blood specimen, presence of PCR inhibitors in blood, and probable latency of the bacterium within macrophages without an active disease are the possible explanations. Overall, molecular detection is still not superior to culture in case of $B$. pseudomallei at this point of time [37].

Available online at: $\underline{\text { www.ijmrr.in }} 244$ | P a g e 


\section{Treatment}

In the medical wards, especially in the medical Intensive Care Units (ICUs), the usual practice of the physicians is to initiate treatment with beta-lactam - beta-lactamase inhibitors (BL-BLIs). These combinations are not recommended for the treatment of melioidosis, but may, to some extent, decrease the bacterial load. However, the patient may come back with relapse [30].

A similar scenario is encountered with surgical speciality, where the most common antibiotic used after drainage of any abscess is Amoxicillin-Clavulanic acid.

Amoxicillin-Clavulanic acid is one of those antibiotics which showed high resistance with melioidosis [30].

Even after the microbiological confirmation and recommendation of the proper treatment, it is found that the treating clinician does not follow the recommendation, as the patient showed clinical improvement with other antibiotics.

Melioidosis may have a protracted course and a chance of relapse if proper antibiotic treatment is not continued for an adequate period of time.

The bacteria are inherently resistant to many antibiotics that are commonly used against Gram-negative nonfermenters - like Penicillin, Ampicillin, first generation and second generation cephalosporins, Gentamicin, Tobramycin, Streptomycin, and Polymyxin.

Ertapenem, Tigecycline, Moxifloxacin, Tetracyclines, Chloramphenicol, the quinolones, and Ceftriaxone, do not appear to be clinically useful in the intensive phase [8].

The treatment of melioidosis is divided into two phases: Intensive phase, consisting of in-patient treatment for at least 10-14 days with Ceftazidime or Carbapenems (Imipenem or Meropenem) and Eradication phase, consisting of treatment with oral TrimethoprimSulfamethoxazole (TMP-SMX) for 3-6 months [30].

Though the conventional intensive regimen consists of I/V Ceftazidime or Carbapenams with oral Doxycyclin or Cotrimoxazole, a recent study proves no significant difference in single versus combination therapy [26].

\section{Prevention}

Melioidosis is a preventable disease. Tourists traveling to endemic areas should be properly cautioned against barefoot walking and recreational activities in water. People with risk factors should be guided to take proper

precautions like protective footwear and mask during rainy season and while going to the paddy fields. Laboratory technicians and research workers should work in inside BSC II facility, and should not try to sniff the colonies from the culture plates.

There is no human vaccine available so far. However, there are researches in animal models involving the use of live attenuated, subunit, plasmid-based DNA, and killed whole-cell vaccine [30].

\section{Road to future}

Melioidosis in India is like tip of iceberg. It is known to be one of the most potent emerging infections in our country so at any time there may be an epidemic of melidiosis. Both the clinicians and the microbiologist have to be suspicious to diagnose the cases.

Regular interactions among them should be arranged at national level. There should be a central reporting system and a surveillance team.

At present the Department of Microbiology, Kasturba Medical College, Manipal is taking initiatives to bring all the interested researchers under one umbrella [30]. 
Moreover, it may play a role of a reference laboratory in future, where bacterial strains can be sent for confirmation after presumptive diagnosis is made in the respective institutions. So definitely we have a long way to go.

Funding: Nil

Conflict of interest: Nil

Permission from IRB: Yes

\section{References}

1. Whitmore A. An account of a glanders-like disease occurring in Rangoon. J Hyg 1913;13: 1-34.

2. Whitmore A, Krishnaswami CS. An account of the discovery of a hitherto underscribed infective disease occurring among the population of Rangoon. Indian Med Gazette 1912;47: 262-7.

3. Stanton AT, Fletcher W. Melioidosis, a new disease of the tropics. Trans Fourth Congr Far East Assoc Trop Med 1921;2:196-8.

4. Yabuuchi, E., Kosako, Y., Oyaizu, H., Yano, I., Hotta, H., Hashimoto, Y., Ezaki, T. and Arakawa, M. (1992), Proposal of Burkholderia gen. nov. and Transfer of Seven Species of the GenusPseudomonas Homology Group II to the New Genus, with the Type Species Burkholderia cepacia(Palleroni and Holmes 1981) comb. nov. Microbiology and Immunology, 36: 1251-75.

5. Raghavan KR, Shenoi RP, Zaer F, Aiyer R, Ramamoorthy P, Mehta MN. Melioidosis in India. Indian Pediatr 1991;28: 184-8.

6. White NJ. Melioidosis. Lancet 2003;361:1715-22.

7. John TJ, Jesudason MV, Lalitha MK, Ganesh A, Mohandas V, Cherian T, Mathai D, Chandy MJ: Melioidosis In India: the tip of the iceberg? Indian J Med Res 1996, 103:62-5

8. Cheng AC, Currie BJ. Melioidosis: Epidemiology, Pathophysiology, and Management. Clin Microbiol Rev $2005 ; 18: 383-416$.

9. Woods DE, DeShazer D, Moore RA, Brett PJ, Burtnick $\mathrm{MN}$, Reckseidler SL, et al. Current studies on the pathogenesis of melioidosis. Microbes Infect 1999;1:15762.

10. Sexton MM, Jones AL, Chaowagul W, Woods DE. Purification and characterization of a protease from Pseudomonas pseudomallei. Can J Microbiol 1994;40:903-10.

11. Häussler S, Nimtz M, Domke T, Wray V, Steinmetz I. Purification and characterization of a cytotoxic exolipid of Burkholderia pseudomallei. Infect Immun 1998;66:158893.

12. Egan AM, Gordon DL. Burkholderia pseudomallei activates complement and is ingested but not killed by polymorphonuclear leukocytes. Infect Immun 1996;64:4952-9.

13. Wong KT, Puthucheary SD, Vadivelu J. The histopathology of human melioidosis. Histopathology 1995;26:51-5.

14. Kespichayawattana W, Rattanachetkul S, Wanun T, Utaisincharoen P, Sirisinha S. Burkholderia pseudomallei induces cell fusion and actin-associated membrane protrusion: A possible mechanism for cell-to-cell spreading. Infect Immun 2000;68:5377-84.

15. Charuchaimontri C, Suputtamongkol Y, Nilakul C, Chaowagul W, Chetchotisakd P, Lertpatanasuwun N, et al. Antilipopolysaccharide II: an antibody protective against fatal melioidosis. Clin Infect Dis 1999;29:813-8.

16. Steinmetz I, Rohde M, Brenneke B. Purification and characterization of an exopolysaccharide of Burkholderia (Pseudomonas) pseudomallei. Infect Immun 1995;63:3959-65.

17. Reckseidler SL, DeShazer D, Sokol PA, Woods DE. Detection of bacterial virulence genes by subtractive hybridization: Identification of capsular polysaccharide of Burkholderia pseudomallei as a major virulence determinant. Infect Immun 2001;69:34-44.

18. Haussler S, Rohde M, Steinmetz I. Highly resistant Burkholderia pseudomallei small colony variants isolated in vitro and in experimental melioidosis. Med Microbiol Immunol (Berl)1999;188:91-7.

Available online at: $\underline{\text { www.ijmrr.in }} 246$ | P a g e 
19. Walsh AL, Smith MD, Wuthiekanun V, Suputtamongkol Y, Chaowagul W, Dance DA, et al. Prognostic significance of quantitative bacteremia in septicemic melioidosis. Clin Infect Dis 1995;21:1498500 .

20. Brown AE, Dance DA, Suputtamongkol Y, Chaowagul W, Kongchareon S, Webster HK, et al. Immune cell activation in melioidosis: increased serum levels of interferon-gamma and soluble interleukin-2 receptors without change in soluble CD8 protein. J Infect Dis $1991 ; 163: 1145-8$.

21. Suputtamongkol Y, Kwiatkowski D, Dance DA, Chaowagul W, White NJ. Tumor necrosis factor in septicemic melioidosis. J Infect Dis 1992;165:561-4.

22. Friedland JS, Suputtamongkol Y, Remick DG, Chaowagul W, Strieter RM, Kunkel SL, et al. Prolonged elevation of interleukin- 8 and interleukin- 6 concentrations in plasma and of leukocyte interleukin-8 mRNA levels during septicemic and localized Pseudomonas pseudomallei infection. Infect Immun 1992;60:2402-8.

23. Simpson AJ, Smith MD, Weverling GJ, Suputtamongkol Y, Angus BJ, Chaowagul W, et al. Prognostic value of cytokine concentrations (tumor necrosis factor, interleukin 6 and interleukin 10) and clinical parameters in severe melioidosis. J Infect Dis 2000;181:621-5.

24. Vasu C, Vadivelu J, Puthucheary SD. The humoral immune response in melioidosis patients during therapy. Infection 2003;31:24-30.

25. Wiersinga WJ, Currie BJ, Peacock SJ. Melioidosis. NEJM 2012;367:1035-44.

26. D Pitaks, S Chusana. Orbital infection caused by Burkhplderia pseudomallei: A mini review. J Infect Dis Antimicrob Agents 2011; 29: 99-103.

27. Mukhopadhyay C, Chawla K, Krishna S, Nagalakshmi N, Rao SP, Bairy I. Emergence of Burkholderia pseudomallei and pandrug-resistant nonfermenters from southern Karnataka, India. Trans Royal Soc Trop Med Hyg 2008;102:S12-7.

International Journal of Medical Research and Review
28. Vidyalakshmi K, Lipika S, Vishal S, Damodar S, Chakrapani M. Emerging clinico-epidemiological trends in melioidosis: Analysis of 95 cases from western coastal India. Int J Infec Dis 2012;16:e491-7.

29. Tiangpitayakorn C, Songsivilai S, Piyasangthong N, Dharakul T. Speed of detection of Burkholderia pseudomallei in blood cultures and its correlation with the clinical outcome. Am J Trop Med Hyg 1997;57:96-9.

30. Purabi Barman, Harish Sidhwa, and Pinak A Shirkhande. Melioidosis: a case report. J Glob Infect Dis. 2011 Apr-Jun; 3(2): 183-186.

31. Dharakul T, Songsivilai S, Smithikarn S, Thepthai C, Leelaporn A. Rapid identification of Burkholderia pseudomallei in blood cultures by latex agglutination using lipopolysaccharide-specific monoclonal antibody. Am J Trop Med Hyg 1999;61:658-62.

32. Jesudason MV, Balaji V, Sirisinha S, Sridharan G. Rapid identification of Burkholderia pseudomallei in blood culture supernatants by a coagglutination assay. Clin Microbiol Infect 2005;11:930-3.

33. Wuthiekanun V, Desakorn V, Wongsuvan G, Amornchai P, Cheng AC, Maharjan B, et al. Rapid immunofluorescence microscopy for diagnosis of melioidosis. Clin Diagn Lab Immunol 2005;12:555-6.

34. Wuthiekanun V, Amornchai P, Chierakul W, Cheng AC, White NJ, Peacock SJ, et al. Evaluation of Immunoglobulin $\mathrm{M}(\mathrm{IgM})$ and IgG Rapid Cassette Test Kits for Diagnosis of Melioidosis in an Area of Endemicity. J Clin Microbiol 2004;42:3435-7.

35. Limmathurotsakul D, Chantratita N, Teerawattanasook N, Piriyagitpaiboon K, Thanwisai A, Wuthiekanun V, et al. Enzyme-linked immunosorbent assay for the diagnosis of melioidosis: Better than we thought. Clin Infect Dis 2011;52:1024-8.

36. Chenthamarakshan V, Kumutha MV, Vadivelu J, Puthucheary SD. Distribution of immunoglobulin classes and IgG subclasses against a culture filtrate antigen of Burkholderia pseudomallei in melioidosis patients. J Med Microbiol 2001;50:55-61.

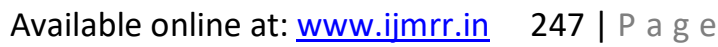


37. Chantratita N, Wuthiekanun V, Limmathurotsakul D, Thanwisai A, Chantratita W, Day NP, et al. Prospective clinical evaluation of the accuracy of $16 \mathrm{~S}$ rRNA real-time
PCR assay for the diagnosis of melioidosis. Am J Trop Med Hyg 2007;77:814-7.

How to cite this article?

Karuna T, Khadanga S, Dugar D. Melioidosis: Indian perspective. Int J Med Res Rev 2014;2(3):242-248. doi:10.17511/ijmrr. 2014.i03.20. 